\title{
Amelioration of Metabolic Syndrome in High Fat Fed Mice by Hydro-ethanolic Fraction of $\boldsymbol{M}$. Iongifolia (J. Koenig)
}

\author{
Dhruv Jha, Papiya Mitra Mazumder* \\ Department of Pharmaceutical Sciences and Technology, Birla Institute of Technology, Mesra, Ranchi, Jharkand -835215, INDIA.
}

\begin{abstract}
Objective: To investigate the effect of hydro-ethanolic fraction of leaves of $M$. longifolia (J. Koenig) on high fat diet induced metabolic disorder. Methods: The M. Iongifolia extract was obtained from the successive extraction followed by fractionation. Ex vivo glucose uptake study was performed. Body weight and blood glucose was checked at regular intervals. After euthanasia serum biochemical parameters, lipid parameters were estimated. Organs were isolated, weighed and fixed in formalin for histopathological analysis. Results: Compared to control, M. longifolia leaf fractions showed significant glucose uptake inhibition in ex vivo studies (rat hemi diaphragm and rat intestinal glucose uptake assay). HFD group showed significant weight increase as compared to normal control. Blood glucose level and glycosylated haemoglobin was found elevated in disease group (obesity and diabetic group). Significant increase in lipid profile of disease group aggravates the diabetic condition. Animal treated with $M$. longifolia leaf fractions $(400 \mathrm{mg} / \mathrm{kg})$ helps in normalisation of liver and white adipose tissue. Conclusion: Metabolic syndrome is an agglomeration of disorders inclusive of increased blood glucose, excess body fat, anomalous triglyceride and cholesterol level, which on joint occurrence leads to diabetes and increased risk of heart disease. Our data suggest that treatment with $M$. longifolia to HFD + STZ group alleviates the diabetes and helps in control of obesity. It may be due to presence of various bioactive constituents.
\end{abstract}

Key words: M. Iongifolia, Ex vivo, Metabolic disorder, In vivo, Blood glucose, BMI.

\section{INTRODUCTION}

Metabolic syndrome is an agglomeration of disorders inclusive of increased blood glucose, excess body fat, elevated blood pressure and anomalous triglyceride and cholesterol level, which on joint occurrence leads to diabetes and increased risk of heart disease. ${ }^{1}$ Metabolic stress is causing an alarming situation for both developing and developed countries as evident from the NHANES reports which shows the escalation of metabolic syndrome by $34 \%$, thus resulting in major health hazards. ${ }^{2}$ Increased mitochondrial stress due to HFD affects mitochondrial electron transport chain leading to imbalance in glucose homeostasis and lipid profile which triggers inflammatory markers leading to obesity and diabetes. ${ }^{3}$ In recent years, use of traditional medicine for therapeutic approach have been rising considerably because of its wide acceptance and relatively lower side effects probably due to the presence of various bioactive constituents having a significant role in the prevention of metabolic disorders. ${ }^{4}$

$M$. longifolia commonly known as mahua or butter nut tree (family Sapotaceae) is evergreen and deciduous in nature, distributed widely across India, Nepal and Sri Lanka. Various parts of $M$. longifolia are used in traditional and folklore system of medicine ${ }^{5-6}$ Bark, flowers and seed parts of this plant has shown the effect on the treatment of epilepsy, diabetes, inflammation, bronchitis, ulcer and other diseases. Leaves
Submission Date: 03-06-2018; Revision Date: 14-08-2018; Accepted Date: 23-10-2018

DOI: 10.5530/ijper.53.1.14 Correspondence:

Dr. Papiya Mitra Mazumder, Department of Pharmaceutical Sciences and Technology, Birla Institute of Technology, Mesra, Jharkand, Ranchi-835215, INDIA. Phone no: +919431327044 E-mail: pmitramazumder@ bitmesra.ac.in

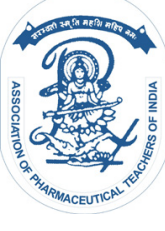

www.ijper.org 
of this plant are used in Cushing's disease, bronchitis and has antioxidant properties. ${ }^{7}$ Literature survey suggest that mainly bark and leaves of Madhuca longifolia exhibits antidiabetic activity but its action against high fat diet associated metabolic disorder is yet to be explored and exhaustive study is yet to be done. ${ }^{6-8}$ Obesity is a major risk factor which contributes to diabetes and metabolic disorder. To curb this problem an effort will be made to check the activity of Madhuca longifolia leaves extract on metabolic disorder. Thus the aim of the present investigation is to evaluate the potential role of hydro-ethanolic fraction of leaves of this plant in maintenance of glucose homeostasis and prevention of metabolic disorder with the help of various ex vivo and in vivo techniques.

\section{MATERIALS AND METHODS}

\section{Chemicals}

Streptozotocin was purchased from Sisco lab, Mumbai, all the other lab chemicals and solvents were obtained from Rankem. Phosphate buffer saline ( $\mathrm{pH} 7.4)$, formalin $(10 \% \mathrm{v} / \mathrm{v})$, accusure glucose estimation kit, autospan kit (TG, HDL , LDL and TC)

\section{Collection, Authentication and Extraction}

Fresh leaves of Madhuca longifolia (J. Koenig) were collected during the month of July and August 2015 and was authenticated by Botanical Survey of India, Howrah. Freshly collected leaves were cleaned and shade dried. The dried leaves were powdered and successively defatted with petroleum ether at $40^{\circ}$ for seven cycles and further successively with chloroform, ethyl acetate and ethanol using soxhlet apparatus. Each collected extracts were filtered through Whatman filter and were concentrated using rotatory evaporator and dried and stored. Then the extract was fractionated further and ethyl acetate fraction (MLEAF), chloroform fraction (MLCF) and hydro-ethanolic fractions (MLHEF) were dried using lyophilizer and subsequently stored in vacuum desiccator. Subsequently preliminary in vitro antioxidant and enzymatic assays were performed and the result showed maximum efficacy in hydro-ethanolic fraction. This was taken for further studies.

\section{Animals}

Healthy swiss albino mice of $18-22 \mathrm{~g}$ of 5 weeks of age were obtained from the animal facility of Birla Institute of Technology. All the experiments were approved by IAEC, as per approval no. (BIT/PH/IAEC/15/2015). The animals were kept in propylene cages and maintained under controlled temperature $(22 \pm 2 \mathrm{C})$ and relative humidity $(55 \pm 5 \%)$ with $12: 12 \mathrm{~h}$ light and dark cycle. All the animals were provided normal diet and water ad libitum.

\section{Ex vivo Anti-diabetic Studies \\ Rat Hemidiaphragm Glucose Diffusion}

Hemi diaphragm was isolated from untreated rats. For hemidiaphragm glucose diffusion, four groups were divided and each group has 5 graduated tests tubes. Control group, insulin treated group and two different dose of extract group. (Control): $2 \mathrm{~g} \%$ glucose in $2 \mathrm{ml}$ Tyrode solution, insulin treated group $2 \mathrm{~g} \%$ glucose in $2 \mathrm{ml}$ Tyrode solution with insulin $(0.62 \mathrm{ml}$ of $0.4 \mathrm{U} / \mathrm{ml})$ and two different dose of extract groups $2 \mathrm{~g} \% \mathrm{glucose}$ in $2 \mathrm{ml}$ Tyrode solution + Hydro-ethanolic extract $(500 \mathrm{mg} / \mathrm{ml})$, $2 \mathrm{~g} \%$ glucose in $2 \mathrm{ml}$ Tyrode solution + Hydro-ethanolic extract $(1000 \mathrm{mg} / \mathrm{ml})$ The rat hemidiaphragms were incubated in test tubes for $30 \mathrm{~min}$ at room temperature with continuous oxygen supply and shaking. Total glucose uptake per $g$ of tissue was calculated as difference between final and initial glucose concentration in incubated media. ${ }^{9-10}$

\section{Rat intestinal Glucose Absorption Preparation of Everted Gut Sac}

Isolated rat intestinal segments were everted and sacs were filled by serosal fluid (incubation media) and were kept in $25 \mathrm{ml}$ Erlenmeyer flasks with $5 \mathrm{ml}$ of same media for oxygenation. After oxygenation, the flask was incubated in an incubator at room temperature in KHB (Krebs- Henseleit bicarbonate buffer) with regular shaking prior to the experiment. Composition of KrebsHenseleit bicarbonate buffer is as follows $(\mathrm{mM} / \mathrm{L})$ : $\mathrm{NaHCO}_{3} 25, \mathrm{KCI} 4.7, \mathrm{CaCl}_{2}, \mathrm{NaCl} 118, \mathrm{MgSO}_{4} 1.2$ and $\mathrm{Na}_{2}$ EDTA 9.7. ${ }^{11}$

\section{Influence of Hydro-ethanolic Extract on Intestinal Glucose Uptake}

Glucose as substrate and plant extract at three different doses was added in same everted sac just before the experiment and incubated for $1 \mathrm{~h}$ at room temperature. After the incubation sacs were removed and the presence of glucose was estimated in serosal fluid and mucosal fluid with help of glucose estimation kit (accusure). Glucose uptake was estimated by amount (PM/g tissue) of glucose taken by mucosal compartment. ${ }^{12}$

\section{Acute Toxicity Studies}

Acute toxicity studies were done according to the OECD guidelines for acute oral toxicity - acute toxic class method (OECD guidelines 423). ${ }^{13}$ The studies 
were carried out for the following fractions. Two female mice were used for each step. According to guidelines, the dose level to be used as the starting dose is selected from one of the four fixed levels, 5, 50,300 and 2000 $\mathrm{mg} / \mathrm{kg}$ body weight. Animals were observed individually after dosing at least once during the first $30 \mathrm{~min}$, periodically during the first $24 \mathrm{~h}$, with special attention given during the first $4 \mathrm{~h}$ and daily thereafter, for a total of 14 days. Attention should be directed to observations of tremors, convulsions, salivation, diarrhea, lethargy sleep and coma.

\section{Induction of Diabetes}

Procured animals for experimentation were fed high fat diet for 15 days for obesity induction and after confirmation of induction of Obesity, out of this few obese animals were injected multiple low dose STZ (dose $30 \mathrm{mg} / \mathrm{kg}$ bw, i.p) after 15 days of HFD. Treatment dosing $(200 \mathrm{mg} / \mathrm{kg}$ and $400 \mathrm{mg} / \mathrm{kg}$ ) was also started in few animal from obese group which were injected with STZ. Haematological parameters were checked at regular interval for confirmation of disease induction. Animals were be divided into the following groups with treatment for 45 days:

Group 1: Normal Control- administered water ad libitum

Group 2: Diabetic control -Treated with STZ (multiple low dose $30 \mathrm{mg} / \mathrm{kg}$ bw, i.p.) and high fat diet

Group 3: Obesity control (treated with high-fat diet for 45 days)

Group 4: Diabetic animal + Treated with MLHEF (200mg/kg bw, p.o.)

Group 5: Diabetic animal + Treated with MLHEF (400mg/kg bw, p.o)

Group 6: Standard - Diabetic animals + Treated with pioglitazone (10mg/kg bw, p.o)

\section{Obesity and Diabetic Parameters Body Weight}

The body weight of different treatment groups were checked from $0^{\text {th }}$ day to $45^{\text {th }}$ day at a regular interval of seven days. ${ }^{14}$

\section{Blood Glucose}

A drop of blood drawn by tail vein was placed on the glucometer strip loaded into the glucometer for blood glucose determination from different groups of experimental animals using calibrated Glucometer at $0^{\text {th }}, 7^{\text {th }}$, $14^{\text {th }}, 21^{\text {st }}, 30^{\text {th }}$ and $45^{\text {th }}$ day. Blood samples were collected from tail vein of the animals under fasting condition. ${ }^{14-15}$

\section{Glycosylated Haemoglobin}

At the end of experimental period on $45^{\text {th }}$ day, blood was withdrawn from retro orbital plexus and collected in the EDTA coated tubes for measuring glycosylated haemoglobin (HbA1C). A haemolysed preparation of whole blood was mixed continuously for $5 \mathrm{~min}$ with a weakly binding cation-exchange resin. The percentage of glycosylated haemoglobin was determined glycosylated haemoglobin was determined by observing absorbance of the Glycosylated haemoglobin $(\mathrm{GHb})$ fraction and total haemoglobin (THb) fraction (Coral HbA1C kit). The ratio of the absorbance of the glycosylated haemoglobin and the total haemoglobin fraction of the control and the sample are used to calculate the percentage of glycosylated haemoglobin in the sample. ${ }^{16}$

Ratio of Ctrl (RC) = Ab control GHb/ Ab Control $\mathrm{THb}$

Test $(\mathrm{RT})=\mathrm{Ab}$ test $\mathrm{GHb} / \mathrm{Ab}$ test $\mathrm{THb}$

$\mathrm{GHb}$ in $\%=$ Ratio of Test (R) $\mathrm{T} /$ Ratio of Control (R) $\times 10$ (Value of Control)

\section{BMI and LEE INDEX}

Obesity parameters that is body mass index (BMI) and Lee Index (LI) were calculated on 1, 7, 15, 30 and $45^{\text {th }}$ day of study. Change in body weight (initial and final B. wt), nasal to anal lenth thoracic and abdominal circumference was measured..$^{17-18}$ The formula is as follows:

Body mass index $(\mathrm{BMI})=$ B.wt $(\mathrm{g}) /$ Height $(\mathrm{cm})$

Lee Index $(\mathrm{LI})=$ B.wt $(\mathrm{g})\{1 / 3\} /$ Nasoanal length $(\mathrm{cm})$

\section{Plasma Lipid Parameters}

Plasma obtained from the retro orbital technique were used to estimate the metabolic parameters. Glucose, triglyceride and total cholesterol levels were measured spectrophotometrically (lambda max: 505nm) using commercially available kits (Autospan). Atherogenic index and Castello ratio was evaluated. ${ }^{3,18-19}$

Atherogenic index: $=(\mathrm{TC}-\mathrm{HDL}) / \mathrm{HDL}$

Castello ratio: $=\mathrm{TC} / \mathrm{HDL}$

\section{Assessment of Organ Weights and Histopathology}

At the end of experiment, animals were euthanized through cervical dislocation and the white adipose tissue, liver, kidney and pancreas were isolated. The organs were weighed and washed with ice-cold $0.1 \mathrm{M}$ phosphate buffer saline $\mathrm{pH} 7.4$ blotted, dried and weighed. The relative liver weight was measured as the percentage ratio of liver weight to body weight. A small portion of the tissue was fixed in formalin for histological evaluation..$^{20-21}$ The remaining tissue was stored at $-20^{\circ} \mathrm{C}$ for not more than 
$12 \mathrm{~h}$ before analysis. The biochemical and pharmacological estimations were carried out after 8 weeks of the experiment.

\section{Statistical Data Analysis}

All the obtained results were expressed as mean $\pm S D$. One way ANOVA and Tukey's test has been used to determine the significance between the respective data of different groups with help of Graph pad prism (v5.1). Values $p \leq 0.05$ were considered to be significant. All the disease control group (obesity control group and diabetic control) were compared to normal control group. All treatment group were compared with disease control group (obesity control group and diabetic control).

\section{RESULTS AND DISCUSSION}

\section{Ex-vivo Diabetic Parameters}

The results of ex vivo diabetic parameters were expressed in Figure 1. It is evident from Figure 1 it can be deduced that in Rat intestinal glucose uptake assay and rat hemi diaphragm glucose assay, hydro-ethanolic fraction has dose-dependent glucose uptake inhibition with respect to control group. Higher dose exhibited significant glucose uptake inhibition with respect to control group $(p \leq 0.001)$.

\section{Evaluation of Body Weight, BMI, Lee Index}

Body weight, BMI and Lee index of the animals were taken on $3^{\text {rd }}, 7^{\text {th }}, 15^{\text {th }}, 30^{\text {th }}$ and $45^{\text {th }}$ day of the experiment. The results of change in these parameters has been shown in Figure 2 and Table 1. There was significant $(p \leq 0.001)$ change in body weight which was observed after 5 weeks in diseased control group with reference to control group while the change was insignificant with respect to treated group $(400 \mathrm{mg} / \mathrm{kg}$ and $200 \mathrm{mg} / \mathrm{kg}$ ). The disease control (obese control and diabetic control) group showed enhanced B.wt as compared to Normal control and treated group $(400 \mathrm{mg} / \mathrm{kg}$ ). Body mass index and lee index of obese group and diabetic group was also found to be significantly $(p \leq 0.05)$ higher than normal control and treated group. Figure 2 (ii, iii and iv) describes the change in body weight, $\mathrm{BMI}$ and lee index between the groups due to intake of HFD, HFD + STZ and treatment.

\section{Blood Glucose and Glycosylated Haemoglobin}

Altered glucose homeostasis was observed in obese and diabetic group at the end of the experiment. The altered level of blood glucose and glycosylated haemoglobin in different groups has been shown in Table 1 and Figure 2. Significant $(p \leq 0.001)$ elevation of blood glucose was found in diabetic group with respect to normal control and treated group. Figure 2 represents the degree of glucose level change between diabetic group vs normal control group and treated group $(400 \mathrm{mg} / \mathrm{kg}$ ) vs diabetic group. Glycosylated haemoglobin was also measured at the end of the $45^{\text {th }}$ day as shown in Table 1. Significant $(p \leq 0.001)$ increase in glycosylated haemoglobin was found in diabetic group with respect to normal control group. Treated group $(400 \mathrm{mg} / \mathrm{kg})$ showed normalisation in glycosylated haemoglobin value as compared to diabetic group.

\section{Serum Lipid Profile}

HDL, LDL, TG and TC was evaluated from the blood serum obtained from the animal through retro orbital on $45^{\text {th }}$ day. The effect in lipoprotein level has been expressed in Figure 3. From the respective data atherogenic index and Castello ratio was also determined in order to check the exacerbation of metabolic disorder. Figure 3 describes that there was significant change was found between diseased control, treated $(400 \mathrm{mg} / \mathrm{kg}$ ) and normal control groups, HDL, LDL, TG and TC value. The diseased group showed higher amount $(\mathrm{p} \leq 0.001)$ of $\mathrm{LDL}, \mathrm{TG}$ and $\mathrm{TC}$ value with respect to control and treated groups while lower HDL value. Elevated Atherogenic index in disease group showed an increased risk of aggravation of disease.

\begin{tabular}{|c|c|c|c|c|c|}
\hline \multicolumn{2}{|c|}{ Table 1: Glycosylated Haemoglobin of HFD and HFD + STZ induced diabetic model. } \\
\hline SL. No & Group Name & $\begin{array}{c}\text { Glycosylated } \\
\text { Hb (\%) }\end{array}$ & $\begin{array}{c}\text { Blood glucose } \\
\text { (after 45 days) }\end{array}$ & $\begin{array}{c}\text { Increase in } \\
\text { Bodyweight }\end{array}$ & $\begin{array}{c}\text { Atherogenic } \\
\text { index }\end{array}$ \\
\hline 1 & Normal control & 4.61 & 111 & 8.47 & 0.97 \\
\hline 2 & Diabetic control & $7.87^{\mathrm{ab}}$ & $205^{\mathrm{ab}}$ & $23.95^{\mathrm{ab}}$ & 2.99 \\
\hline 3 & obesity control & 6.02 & 186 & 25.12 & $4.01^{\mathrm{ab}}$ \\
\hline 4 & MLHEF (Fraction 1) - 200mg/kg b.wt. & 6.92 & 162 & 21.33 & 2.011 \\
\hline 5 & MLHEF (Fraction 2) - 400 mg/kg b.wt. & 5.81 & 139 & 19.16 & 1.11 \\
\hline 6 & Standard & 5.42 & 122 & 16.30 & 0.91 \\
\hline
\end{tabular}

$a=$ significant difference $(p \leq 0.01)$ with respect to normal control

$\mathrm{b}=$ significant difference $(p \leq 0.01)$ with respect to treated group $(400 \mathrm{mg} / \mathrm{kg})$ 

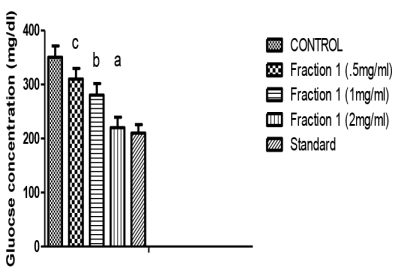

Groups

$\mathrm{i}$

Figure 1: The result of rat (i) intestinal glucose uptake and (ii) rat hemidiaphragam glucose uptake inhibition of leaves revealed that hydro-ethanolic $(50 \%)$ fraction possess significant $(p<0.001)$ inhibition potential than control. The data are expressed as the mean \pm standard deviation $(n=6)$. All the statistical analysis was done by one way ANOVA followed by Tukey's test.

Where $a={ }^{* * *}$ w.r.t control, $b={ }^{* *}$ w.r.t control $c=$ ns w.r.t control
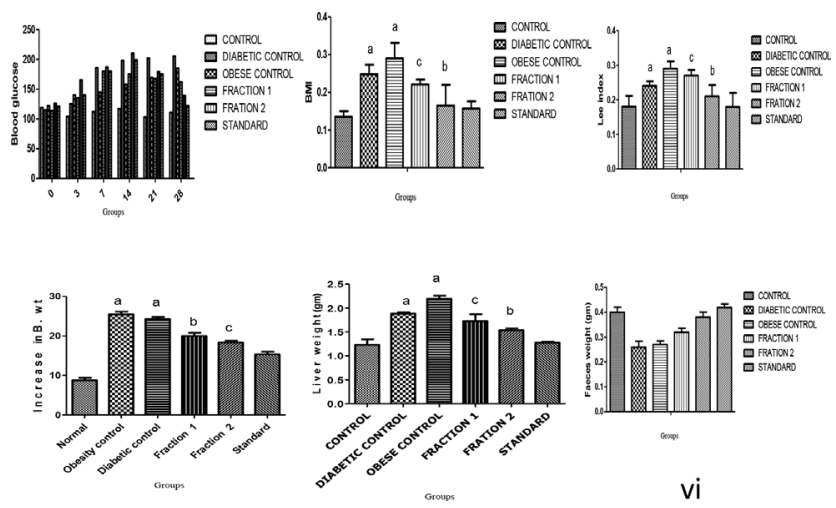

Figure 2: The results showed significant change in, (i) blood glucose, (ii)BMI, (iii)LEE index, (iv)Body weight, (v) Liver weight and (vi) faeces weight between treated and diabetic group $(p<0.001)$. The data are expressed as the mean \pm standard deviation $(n=6)$. Where $a={ }^{* * *}$ w.r.t control, $b={ }^{* * *}$ w.r.t diabetic control $c=n s$ w.r.t diabetic control. All the statistical analysis was done by one way ANOVA followed by Tukey's test.

\section{Organ Weight and Histopathological Analysis}

The histopathological change in different organ has been shown in Figure 4. Liver, white adipose tissue and kidney weight were taken after euthanasia. Figure 2 showed marked increase $(p \leq 0.05)$ in liver and white adipose tissue weight in obese and diabetic group. For histopathological studies liver, white adipose tissue and pancreas were removed and fixed in 10\% formalin and later $\mathrm{H}$ and $\mathrm{E}$ staining was performed. Morphological observation showed difference in liver colour between the diseased and control group. From Figure 4 histopathological changes have been depicted, it showed fatty accumulation in hepatocytes as well cellular damage to liver cell of obese and diabetic group. On the other hand
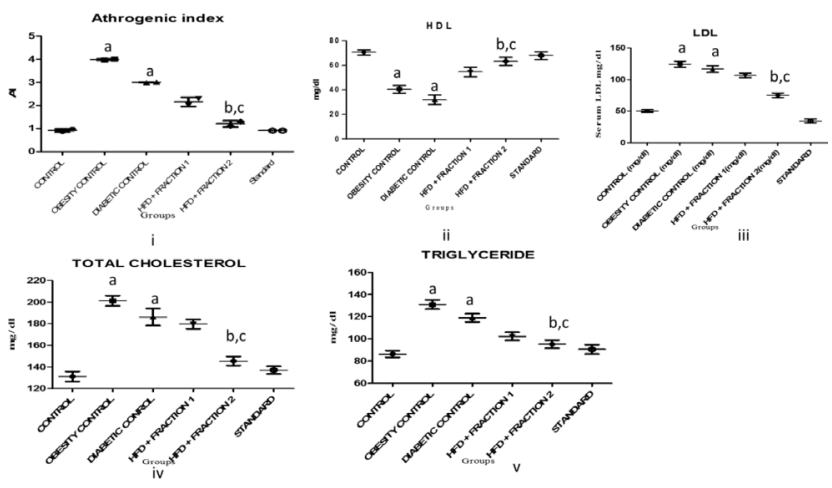

Figure : 3 The graph showed significant $(p<0.001)$ difference in (i) Atherogenic index (ii)HDL, (iii) LDL, (iv) Total Cholesterol Level and (v) Triglyceride between fraction treated and diabetic group. The data are expressed as the mean \pm standard deviation $(n=6)$. Where $a={ }^{* * *}$ w.r.t control, $b={ }^{* * *}$ w.r.t diabetic control $c={ }^{* * *}$ obesity control. All the statistical analysis was done by one way ANOVA followed by Tukey's test.
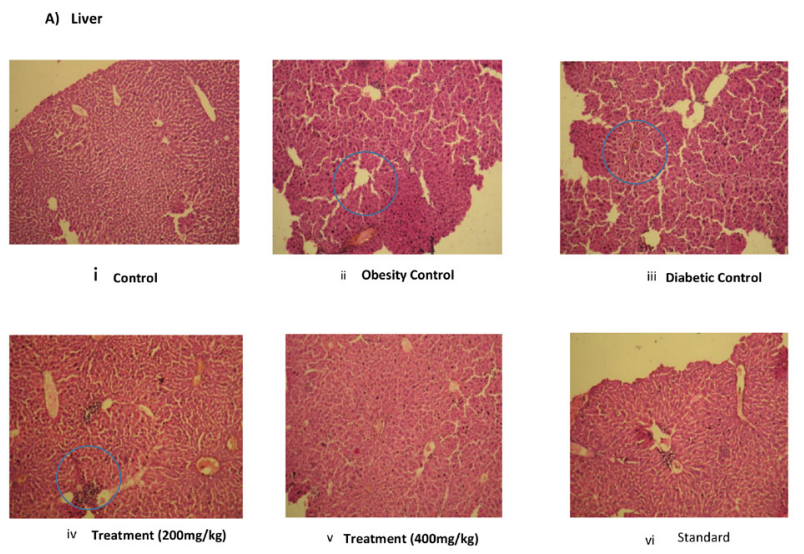

B) White Adipose tissue
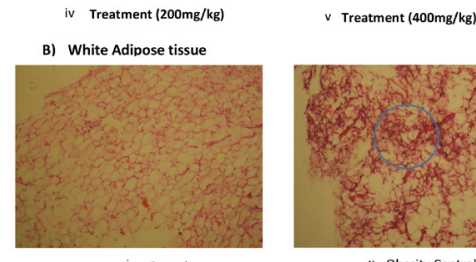

vi Standard
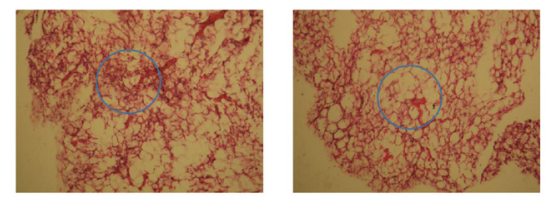

ii Obesity Control
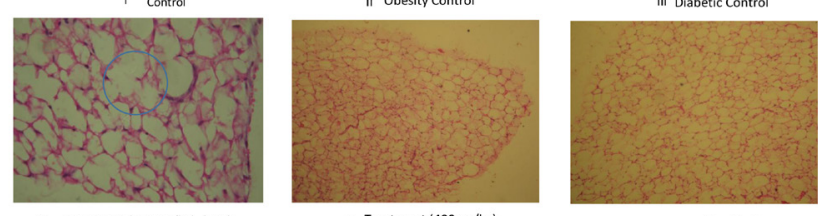

V Treatment $(200 \mathrm{mg} / \mathrm{kg})(40 \mathrm{x})$

$\checkmark$ standard

Figure 4: Histopathological evaluation (10x) Of A) liver section and B) White adipose tissue (i) normal control (ii) obesity control (iii) diabetic control (iv) MLHEF $200 \mathrm{mg} / \mathrm{kg}$ (v) MLHEF $400 \mathrm{mg} / \mathrm{kg}$ (vi)Standard. Circled area shows degeneration and deformity in tissue structure in obese and diabetic group while tissue structure was normalised in treated groups. In liver cells fatty deposition and cell inflammation was observed in disease control group. In white adipose tissue irregular cell expansion and structural breakdown was seen. 
(MLHEF) treated group $(400 \mathrm{mg} / \mathrm{kg})$ showed increased healthy hepatocytes. In white adipose tissue increased inflammation and disrupted structure was observed in disease group (obese and diabetic). WAT has higher amount of inflammation against the diabetic group. The degree of inflammation was decreased in treated group $(400 \mathrm{mg} / \mathrm{kg})$ but not much effect was observed in low dose treatment group $(200 \mathrm{mg} / \mathrm{kg})$. However Pancreas showed in-significant changes in all the groups.

\section{DISCUSSION}

In recent times metabolic disorders like obesity and diabetes are widely considered as a foremost cause of chronic diseases. Abnormalities like obesity can make people more prone to various disorders like cardiovascular disorder, diabetes. ${ }^{2,22}$ Diet, nutrition and exercise play a key role in prevention and treatment of metabolic diseases. Research show that herbal extracts have a significant role in amelioration of the metabolic syndrome. ${ }^{3,23}$ Elevated body weight, imbalanced glucose homeostasis and regulated lipid profile are a few of the primary key characteristics of metabolic disorder like as obesity, diabetes or cardiac diseases. The increased shift in these haematological and body parameters can cause serious damage to body cells leading to organ failures. ${ }^{22-23}$ High fat containing items are mostly used diet in today's population. Its regular and high intake will be the cause of many diseases in coming era, hence its balance is one of the major concern. ${ }^{24}$ In this investigation we studied the effect of MLHEF on metabolic disorder on murine model and analysed the various serum, morphological and histopathological parameters.

Several researchers reported an increase in body weight as important criteria in high fat diet induced diabetic murine. ${ }^{13-14,23}$ In this study, it was observed that regular intake of high fat diet leads to increase in body weight and fat deposition. All the groups showed similar weight enhancement up to 3 weeks of study. In subsequent weeks, increase in body weight was observed but the change between diseased group (obese and diabetic group) and normal control was more than diseased group and treatment group (400mg/ kg and $200 \mathrm{mg} / \mathrm{kg}$ ). The food intake was also high in diseased group even after 3 weeks of study. The diseased groups showed marked weight gain while that in normal control was less. The treatment groups $(400 \mathrm{mg} / \mathrm{kg}$ and $200 \mathrm{mg} / \mathrm{kg}$ ) showed relatively less weight increment with respect to disease groups which confirms it action against weight gain. BMI and Lee index also showed a similar pattern and significant increment in their value in diseased groups versus the normal control and treated group
(400 mg/kg). This data support change in metabolism, occurring inside the body due to high fat diet and also weight gain controlling activity of $M$. longifolia.

Increased high fat deposition induces the insulin secretion in order to maintain glucose balance. The increment of insulin for longer period leads to insulin resistance and its sensitization leading to alteration of glucose homeostasis. ${ }^{23-24}$ High fat diet also leads to accumulation of adipocytes which on high amount starts inflammatory pathway that is stimulation of TNF $\alpha$, cytokines and others. These inflammatory markers also aggravates the condition thus enhances the chance of metabolic disorder. ${ }^{4,23}$ In the present investigation, significant elevation in glucose level and glycosylated haemoglobin was observed in diabetic group while normalising effect was observed in high dose treated group thus proving its anti diabetic potential. Diabetic group showed about $60 \%$ of glucose and glycosylated haemoglobin increment while treated group $(400 \mathrm{mg} / \mathrm{kg})$ showed reduction up to $40 \%$ in these parameter proving antidiabetic effect of MLHEF. Ex vivo study supports the glucose maintaining potential of $M$. longifolia as marked decrease $(30 \%)$ in glucose uptake was observed in rat intestine and diaphragm.

Long term consumption of High fat imbalances the serum and also tissue lipid profile. The imbalance is characterized by increase in serum LDL, TG and TC level as well as decrement HDL level which is one of possible marker of occurrence of metabolic disorder., ${ }^{3,20,23}$ High atherogenic index and Castello ratio proposes increased chances of metabolic alteration. Several experiments had already proved that hyperlipidaemia and atherosclerosis incidence is enhanced in diabetes. ${ }^{25}$ In the present study, reducing potential of LDL, TG and TC by $M$. longifolia was explored. Our investigation found that MLHEF at higher dose $(400 \mathrm{mg} / \mathrm{kg})$ significantly reduces the serum lipid content i.e. LDL, TG and TC levels which was elevated by high fat diet consumption. Thus it can be concluded that $M$. longifolia exhibits serum lipid modulating potential and has a beneficial action against obesity and diabetes.

In animals fed with high fat diet and HFD + low dose STZ, no noticeable change was observed as they appeared healthy and no sign of pathological abnormality was found during experimental period. Various histopathological study reports the increased liver mass and hepatocyte alteration like presence of macrophages, cellular damage in obese and type 2 diabetic animals. ${ }^{23-24}$ Presence of inflammatory cells in WAT is also a marker for detection of obesity linked diabetes. ${ }^{24}$ The cellular changes and presence of inflammatory bodies in liver and adipose cells leads to insulin resistance and insulin 
sensitivity causing metabolic disorder. ${ }^{25-26}$ The isolated liver and white adipose tissue weighs significantly higher in diseased group as compared to normal control and treatment group. The comparative study of histopathology of liver and white adipose tissue between disease control (obesity and diabetic control), normal control and MLHEF treated group $(400 \mathrm{mg} / \mathrm{kg}$ ) showed marked changes. Disease group showed liver degeneration, swollen cytoplasm, steatosis and micro vesicular vacuoles..$^{26-28}$ While treatment $(400 \mathrm{mg} . \mathrm{kg}$ ) decreased the degeneration and vacuoles in liver. Histopathological assessment of white adipose tissue showed reduced fat accumulation in treated group which was enlarged in diseased group (obesity control and diabetic control). The size of adipocytes were also decreased w.r.t to diseased group (obesity control). ${ }^{28-29}$ None of the murines showed gross and significant microscopic renal or pancreatic abnormality.

\section{CONCLUSION}

Summarizing the present investigation it can be concluded that Hydro-ethanolic leaf fraction of $M$. longifolia exhibits potential effect against metabolic disorder. In this animal study, MLHEF controls the weight gain and helps in normalisation of serum lipid profile and glucose homeostasis as reduced fat weight and blood glucose level was observed in treated group.

\section{ACKNOWLEDGMENT}

The authors would like to acknowledge the Department of Pharmaceutical sciences and Technology for providing the facilities. Authors are grateful to UGC and AICTE for providing financial assistance.

\section{CONFLICT OF INTEREST}

The author declares no conflict of interest.

\section{ABBREVIATIONS}

p.o: Per os; i.p: Intraperitoneal; HFD: High fat diet; STZ: Streptozotocin; WAT: White adipose tissue; BMI: Body mass index; B.wt: Body weight; HDL: High density lipoproteins; LDL: Low density lipoproteins; TG: Triglycerides; TC: Total cholesterol; M. longifolia: Madhuca longifolia; MLHEF: M. longifolia hydro ethanolic fraction; TNF: Tumour necrosis factor.

\section{REFERENCES}

1. Zhou X, Han D, Xu R, Li S, Wu H, Qu C. A model of metabolic syndrome and related diseases with intestinal endotoxemia in rats fed a high fat and high sucrose diet. PloS One. 2014;9(12):115-48.
2. Moore JX, Chaudhary N, Akinyemiju T. Metabolic Syndrome Prevalence by Race/Ethnicity and Sex in the United States, National Health and Nutrition Examination Survey, 1988-2012. Prev Chronic Dis. 2017;14:E24.

3. Sheikh Y, Maibam BC, Biswas D, Laisharm S, Deb L, Talukdar NC. Antidiabetic potential of selected ethno-medicinal plants of north east India. J Ethnopharmacol. 2015;171:37-41.

4. Tabatabaei-Malazy O, Larijani B, Abdollahi M. Targeting metabolic disorders by natural products. J Diabetes Metab Disord. 2015;14(1):57.

5. Ramadan MF, Mohdaly AA, Assiri AM, Tadros M, Niemeyer B. Functional characteristics, nutritional value and industrial applications of Madhuca longifolia seeds: an overview. J Food Sci Tech. 2016;53(5):2149-57.

6. Akshatha K, Mahadeva MS, Lakshmi DN. Ethnomedical uses of madhuca longifolia--a review. Int J Life Sci Pharma Res. 2013;3(1):44-53.

7. Yadav P, Singh D, Mallik A, Nayak S. Madhuca longifolia (Sapotaceae), a review of its traditional uses, phytochemistry and pharmacology. Int J Biomed Res. 2012;3(7):291-305.

8. Jha D, Mazumder PM. Biological, chemical and pharmacological aspects of Madhuca longifolia. APJTM. 2018;11(1):9

9. Nirubama K, Kanchana G, Rubalakshm G. Evaluation of Free radicals scavenging and glucose uptake by isolated rat hemi-diaphragm study of Andrographis echioidesan indigenous Medicinal Plant. Int J Curr Microbiol App Sci. 2015;4(6):576-83.

10. Randle PJ. The assay of insulin in vitro by means of the glucose uptake of the isolated rat diaphragm. J Endocrinol. 1956;14(1):82-86.

11. Therasa SV, Thirumalai T, Tamilselvan N, David E. In-vivo and ex-vivo inhibition of intestinal glucose uptake: a scope for antihyperglycemia. J Acute Dis. 2014;3(1):36-40.

12. Bhowmik A, Khan LA, Akhter M, Rokeya B. Studies on the antidiabetic effects of Mangifera indica stem-barks and leaves on nondiabetic, type 1 and type 2 diabetic model rats. Bangladesh J Pharmacol. 2009;4(2):110-14.

13. OECD/OCDE 423, OECD Guideline for Testing of Chemicals, Acute Oral Toxicity

14. eAcute Toxic Class Method, Environment Directorate Organisation For Eco-nomic Co-Operation And Development, Paris. (Adopted: 17 th December 2001).

15. Ghosh R, Dhande I, Kakade V, Vohra R, Kadam V, Mehra. Antihyperglycemic activity of Madhuca longifolia in alloxan -induced diabetic rats. The Internet J Pharmacol. 2008;6(2).

16. Kaur G. Amelioration of obesity, glucose intolerance and oxidative stress in high-fat diet and low-dose streptozotocin-induced diabetic rats by combination consisting of curcumin with piperine and quercetin. ISRN Pharmacol. 2012;8:2012.

17. Jiao $Y$, Wang $X$, Jiang $X$, Kong F, Wang S, Yan C. Antidiabetic effects of Morus alba fruit polysaccharides on high-fat diet-and streptozotocin-induced type 2 diabetes in rats. J Ethnopharmacol. 2017;199:119-27.

18. Novelli EL, Diniz YS, Galhardi CM, Ebaid GM, Rodrigues HG, Mani F. Anthropometrical parameters and markers of obesity in rats. Laboratory Animals. 2007;41(1):111-9.

19. Akter F, Rahman MM, Mostofa M, Chowdhury EH. Anti-diabetic effect of neem and spirulina in alloxan induced diabetic mice. IJCRR. 2014;2(4):124-34.

20. Rani N, Sharma SK, Vasudeva N. Assessment of antiobesity potential of Achyranthes aspera Linn. seed. J Evid-Based Complementary Altern Med. 2012;2012.

21. Kasabri V, Al-Hallaq EK, Bustanji YK, Abdul-Razzak KK, Abaza IF, Afifi FU. Antiobesity and antihyperglycaemic effects of Adiantum capillus-veneris extracts: in vitro and in vivo evaluations. Pharm Biol. 2017;55(1):164-72.

22. Sunil V, Shree N, Venkataranganna MV, Bhonde RR, Majumdar M. The antidiabetic and anti-obesity effect of Memecylon umbellatum extract in high fat diet induced obese mice. Biomed. Pharmacother. 2017;89:880-6.

23. Jaiswal YS, Tatke PA, Gabhe SY, Vaidya AB. Antidiabetic activity of extracts of Anacardium occidentale Linn. leaves on n-streptozotocin diabetic rats. J Tradit Complement Med. 2017;7(4):421-7.

24. Cui M, Kim HY, Lee KH, Jeong JK, Hwang JH, Yeo KY. Antiobesity effects of kimchi in diet-induced obese mice. J Ethnic Foods. 2015;2(3):137-44.

25. Antony PJ, Gandhi GR, Stalin A, Balakrishna K, Toppo E, Sivasankaran K. Myoinositol ameliorates high-fat diet and streptozotocin-induced diabetes in rats through promoting insulin receptor signaling. Biomed Pharmacother. 2017;88:1098-113. 
Seyedan A, Alshawsh MA, Alshagga MA, Mohamed Z. Antiobesity and lipid lowering effects of Orthosiphon stamineus in high-fat diet-induced obese mice. Planta Med. 2017;83(08):684-92.

27. Soltis AR, Kennedy NJ, Xin X, Zhou F, Ficarro SB, Yap YS. Hepatic Dysfunction Caused by Consumption of a High-Fat Diet. Cell Reports. 2017;21(11):3317-28.

28. Hassan NF, Soliman GM, Okasha EF, Shalaby AM. Histological, immunohistochemical and biochemical study of experimentally induced fatty liver in adult male albino rat and the possible protective role of pomegranate. J Microsc Ultrastruct. 2018;6(1):44-55.

29. Fischer IP, Irmler M, Meyer CW, Sachs SJ, Neff F, DeAngelis MH. A history of obesity leaves an inflammatory fingerprint in liver and adipose tissue. Int J Obes. 2018;42(3):507.

30. Poret JM, Souza-Smith F, Marcell SJ, Gaudet DA, Tzeng TH, Braymer HD. High fat diet consumption differentially affects adipose tissue inflammation and adipocyte size in obesity-prone and obesity-resistant rats. Int $\mathrm{J}$ Obes. 2018;42(3):535-41.
PICTORIAL ABSTRACT

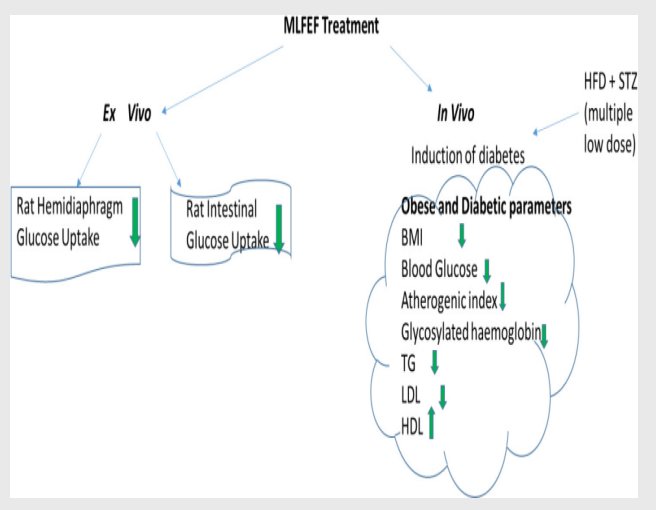

\section{About Authors}
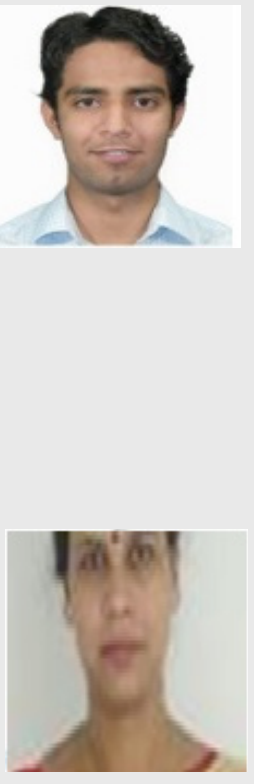

Dhruv Jha: Obtained post graduate degree in Pharmacology from Department of Pharmaceutical Sciences and Technology, Birla Institute of Technology, Mesra in 2014. Currently pursuing Ph.D under guidance of $\mathrm{Dr}$. (Mrs.) Papiya Mitra Mazumder in the field of Pharmacology in the same department.

\section{Summary}

- The present study is focused on amelioration of HFD+STZ induced metabolic disorder with the administration of $M$. longifolia hydroethanolic fraction of leaves (MLHEF) through ex vivo and in vivo studies. Chronic HFD administration leads to metabolic changes finally causing the metabolic disorders like obesity, diabetes and cardiovascular diseases. Through ex vivo studies it was depicted that MLHEF exhibits significant glucose uptake inhibition across the intestinal and diaphragm membranes thus it may have potential against metabolic disease. This was further confirmed through in vivo studies by observing the change in biochemical, metabolic and histopathological parameters like BMI, blood glucose, glycosylated haemoglobin and lipoprotein profile. MLHEF showed significant reduction in elevated blood glucose and lipoprotein levels along with maintaining the BMI and body weight. Histopathological studies supported the MLHEF action as normalisation in liver tissue and WAT was observed MLHEF treated animals as compared diseased control. Thus from this study it can be elucidated that MLHEF exhibits potential action for amelioration of metabolic disorders

Dr. (Mrs.) Papiya Mitra Mazumder: Is a Professor in the Department of Pharmaceutical Sciences and Technology, Birla Institute of Technology, Mesra. She is working on areas concerning Diabetes, metabolic disorder, Neurological Disorders, Toxicology and effect of Bioactive Molecules of Natural and Synthetic Origins.

Cite this article: Jha D, Mazumder PM. Amelioration of Metabolic Syndrome in High Fat Fed Mice by Hydro-ethanolic Fraction of M. Iongifolia (J. Koenig). Indian J of Pharmaceutical Education and Research. 2019;53(1):104-11. 